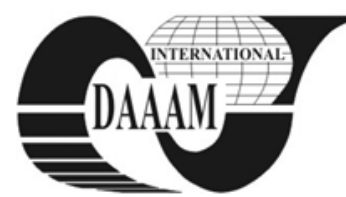

Annals of DAAAM for 2011 \& Proceedings of the 22nd International DAAAM Symposium, Volume 22, No. 1, ISSN 1726-9679 ISBN 978-3-901509-83-4, Editor B. Katalinic, Published by DAAAM International, Vienna, Austria, EU, 2011 Make Harmony between Technology and Nature, and Your Mind will Fly Free as a Bird

Annals \& Proceedings of DAAAM International 2011

\title{
FORMATION OF IMC THE INTERFACE OF SNAGCU1,0BI SOLDER WITH CU SUBSTRATE
}

\author{
KOVARIKOVA, I[ngrid]; SIMEKOVA, B[eata]; HODULOVA, E[rika] \& ULRICH, K[oloman]
}

\begin{abstract}
The effects of Bi addition on the intermetallic phase formation in the lead-free solder joints of SnAgCul,OBi (composition given in weight \%) with copper substrate are studied. The aged interfaces were analysed by the optical microscopy and energy dispersive $x$-ray spectroscopy (EDX) microanalysis. The mechanism of the $\mathrm{Cu}_{6} \mathrm{Sn}_{5}$ layer growth is discussed and the conclusions for the optimal solder chemical composition are presented.
\end{abstract}

Key words: lead-free solder, intermetallic compound, formation, growth, annealing

\section{INTRODUCTION}

Increasing environmental and health concerns about the lead toxicity limit of traditional $\mathrm{Sn}-\mathrm{Pb}$ alloys in soldering technology and stimulate the development of alternative, leadfree solder alloys for electronic applications (Suganuma, 2004; Viňáš et al., 2010). Among the currently considered compositions, ternary eutectic $\mathrm{Sn}-\mathrm{Ag}-\mathrm{Cu}$ alloys have received a lot of attention due to their reasonable melting temperature (217 ${ }^{\circ} \mathrm{C}$ ), increased strength and a lower wetting angle comparing to binary Sn-Ag eutectic alloys (Madeni et al., 2006; Viňáš et al., 2010). $\mathrm{Ag}$ and $\mathrm{Cu}$ elements are used in low concentrations and thus, they are not considered to be an environmental hazard. Nevertheless, challenges remain with respect to the relatively high melting point of these alloys. The melting point of a traditional Sn-Pb solder is only $183{ }^{\circ} \mathrm{C}$. In order to decrease the melting point of $\mathrm{Sn}-\mathrm{Ag}-\mathrm{Cu}$ alloys, additional elements in low concentrations are needed. Bismuth is potential candidate that may significantly lower the melting of the $\mathrm{Sn}-\mathrm{Ag}-\mathrm{Cu}$ eutectic. Furthermore, this element is able to increase the solder's mechanical strength and improve the wettability (***, 2007; ***, 2004).

\section{EXPERIMENT}

The lead free solder samples were prepared by melting the pure metals ( $\mathrm{Sn}, \mathrm{Ag}, \mathrm{Cu}, \mathrm{Bi}$ ), in the respective concentrations, in alumina crucibles. The used metals were of $99.99 \%$ purity. The chemical compositions of the samples, measured by the energy dispersive x-ray spectrometry (EDX, JEOL-JXA-840A), are given in Table 1 . The technical copper plate $(99.99 \%)$ was used as the substrate material. The copper surface was grinded, polished by diamond paste ( $1 \mu \mathrm{m}$ finish) and cleaned by the ultrasonic cleaner.

The soldering of the copper plate was conducted at $250{ }^{\circ} \mathrm{C}$ for $5 \mathrm{~s}$. After the soldering, the samples were quenched to the room temperature. The joints were subsequently aged at temperatures of $130-170{ }^{\circ} \mathrm{C}$ for 2-16 days in a convection oven. The samples were gradually taken from the furnace after $2,4,8,12$ and 16 days. The samples were mounted in the epoxy resin and the cross sections were made. Prior to the analysis, the interface was polished with the diamond paste and finally etched in a nitric acid solution $(5 \% \mathrm{HNO} 3+2 \% \mathrm{HCl}+$ 93\% methanol) for 2-4 s. The microstructure of the soldered joints and the morphology of intermetallic phases were investigated by the optical microscope. The chemical composition of the phases was investigated by the EDX microanalysis (JEOL-JXA-840A).

\begin{tabular}{lcccc}
\hline Acronym & Sn & Ag & Cu & Bi \\
\hline SACB & 97,5 & 1 & 0,5 & 1
\end{tabular}

Tab. 1. Chemical composition (in weight \%) of the investigate solder

\section{RESULTS}

\subsection{Macroscopic analysis}

The microstructure of the SACB-Cu solder joint is presented in Figure 1. Similarly to the previous case, the interface layer between the materials immediately after the soldering consisted only of a scallop-shaped $\mathrm{Cu}_{6} \mathrm{Sn}_{5}$. The average thickness of $\mathrm{Cu}_{6} \mathrm{Sn}_{5}$ was $0.85 \mu \mathrm{m}$. During the subsequent solid-state ageing, this layer continued to grow. $\mathrm{Cu}_{6} \mathrm{Sn}_{5}$ layer is formed by nucleation during soldering between the solid copper substrate and liquid Sn-based lead free solder. At early stages, the layer is expected to grow in the horizontal direction until the grains start impinging one another. The scallop-like shape of this phase is probably a result of the grain coarsening. The scallop-like shape disappears at later stages of ageing which suggests a change in the growth mechanism to the steady growth in the perpendicular direction to the interface.
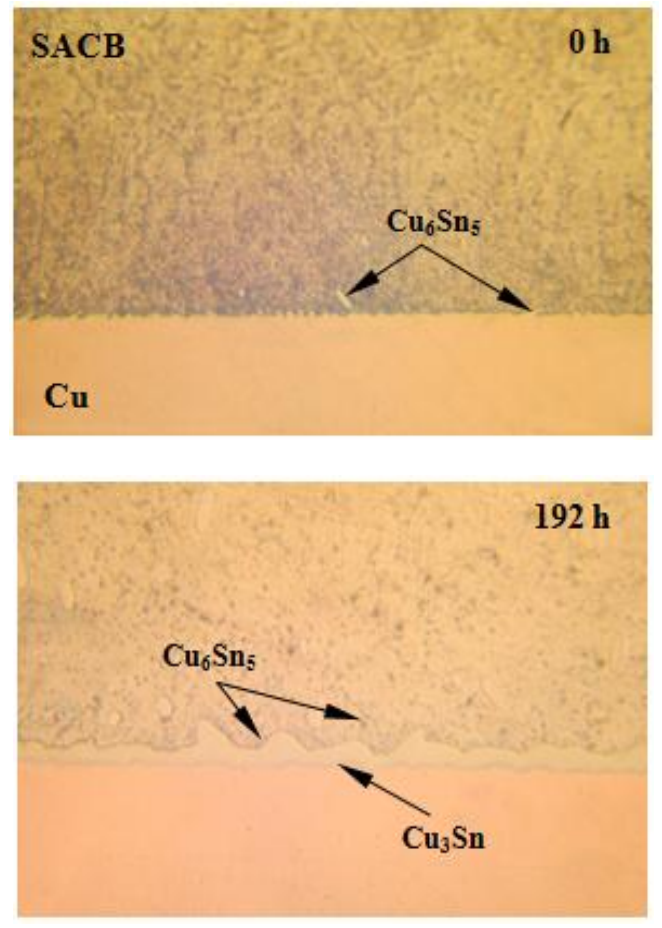


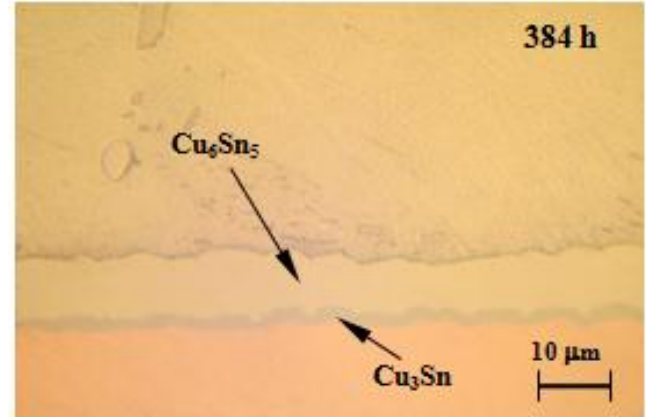

Fig. 1. Microstructure evolution of the $\mathrm{Cu} / \mathrm{SACB}$ interface after soldering and solid state ageing at $150^{\circ} \mathrm{C}$ for $0,192,384$ hours

\subsection{Chemical analysis}

The chemical composition of the cross section is presented in Figure 2. Bismuth does not significantly influence the chemical composition of intermetallic phases. This is probably due to the low concentration. The element is located mostly in the solder bulk. Nevertheless, bismuth seems to suppress the formation of the second layer, $\mathrm{Cu}_{3} \mathrm{Sn}$. The thickness is smaller comparing to the $\mathrm{Cu}_{3} \mathrm{Sn}$ layer formed at the $\mathrm{Cu}-\mathrm{SAC}$ interface.

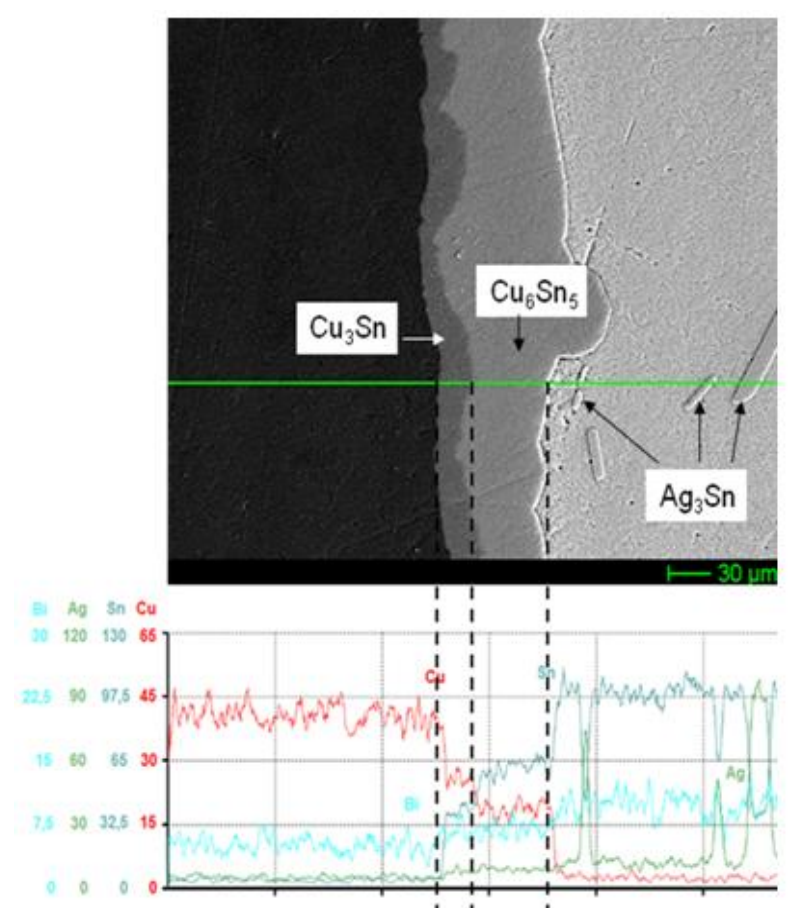

Fig. 2 Element distribution across the $\mathrm{Cu} / \mathrm{SACB}$ interface, measured by EDX, after solid state ageing for $384 \mathrm{~h}$

\subsection{Growth kinetics of intermetallic phases}

The time evolution of the $\mathrm{Cu}_{6} \mathrm{Sn}_{5}$ layer thickness is given in Fig. 3. The $\mathrm{Cu}_{6} \mathrm{Sn}_{5}$ layer grows with a significantly higher rate comparing to $\mathrm{Cu}_{3} \mathrm{Sn}$. The layer growth follows the parabolic rate law

$$
x=\mathrm{k}_{\mathrm{p}} \sqrt{t}+\mathrm{x}_{0}
$$

In this equation $x$ is the layer thickness, $t$ is the ageing time, $\mathrm{k}_{\mathrm{p}}$ is the parabolic rate constant and $\mathrm{x}_{0}$ is the layer thickness before ageing (at $t=0 \mathrm{~h}$ ).

The growth kinetics is thermally activated. The parabolic rate constants obey the Arrhenius equation

$$
\log \mathrm{k}_{\mathrm{p}}=\log \mathrm{A}-2.303 \frac{E_{\mathrm{A}}}{\mathrm{R} T}
$$

In this equation, $\mathrm{A}$ is the pre-exponential factor, $E_{\mathrm{A}}$ is the activation energy, $\mathrm{R}$ is the molar gas constant and $T$ is the ageing temperature. The apparent activation energy for the $\mathrm{Cu}_{6} \mathrm{Sn}_{5}$ layer formation is $71 \mathrm{~kJ} \mathrm{~mol}^{-1}$. Bismuth decreases the rate of $\mathrm{Cu}_{3} \mathrm{Sn}$ layer formation.

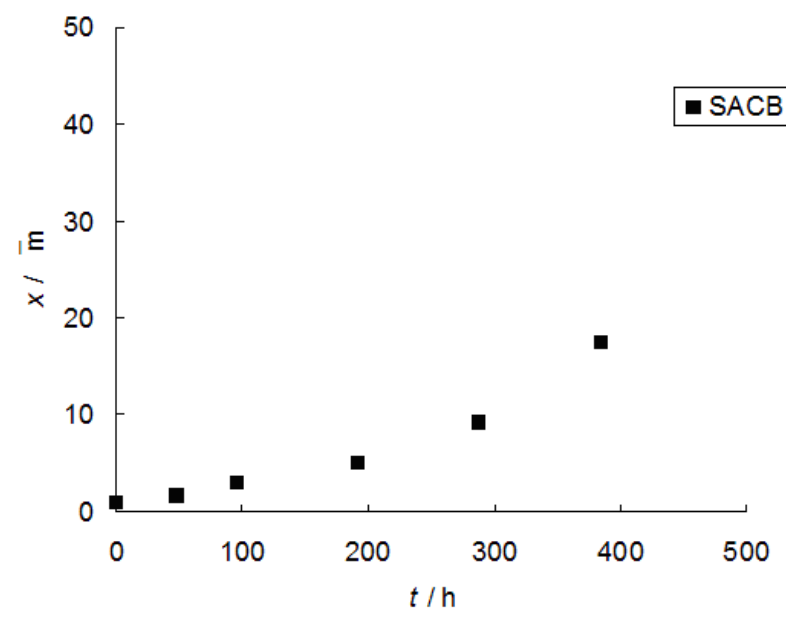

Fig. 3. Thickness of the $\mathrm{Cu}_{6} \mathrm{Sn}_{5}$ layer versus ageing time for solder system SACB

\section{CONCLUSION}

The effect of bismuth in $\mathrm{Sn}-\mathrm{Ag}-\mathrm{Cu}$ solders on the kinetics of intermetallic phase formation at the solder-copper interfaces was investigated. The interface layer consisted of two parallel layers - $\mathrm{Cu}_{3} \mathrm{Sn}$ and $\mathrm{Cu}_{6} \mathrm{Sn}_{5} \cdot \mathrm{Cu}_{6} \mathrm{Sn}_{5}$ was formed during soldering and grew parabolically during subsequent solid state ageing. $\mathrm{Cu}_{3} \mathrm{Sn}$ was formed during solid state ageing and its growth rate was decreased by $\mathrm{Bi}$ additions in the lead-free solder. It is suggested that $\mathrm{Cu}_{3} \mathrm{Sn}$ grows by $\mathrm{Sn}$ diffusion. Bismuth can substitute $\mathrm{Sn}$ in intermetallic compounds, $\mathrm{Cu}_{3}(\mathrm{Sn}, \mathrm{Bi})$ compounds form at $\mathrm{Cu}_{3} \mathrm{Sn}$ grain boundaries where they inhibit Sn diffusion.

Future research will address to investigation in lead-free solders based on $\mathrm{SnAgCu}$ containing under $1 \% \mathrm{Bi}$ and $\mathrm{In}$, studying their physical, mechanical and soldering properties.

\section{ACKNOWLEDGEMENTS}

This paper was supported by projects VEGA 1/0111/10.

\section{REFERENCES}

Madeni, J., Liu. S. (2006): Intermetallics formation and growth at the interface of Tin-based solder alloys and copper substrates. Second Int. Brazing and Soldering Conference, San Diego, CA, February

Suganuma, K. (2004): Lead-Free Soldering in Electronic. Science, Technology, and Environmental Impact. New York. Marcell Dekker, ISBN 0-8247-4102-1

Viňáš, J., Kaščák, L', Ábel, M., Draganovská, D. (2010). The quality analyze of MIG soldering zinc-coated steel sheets by destructive testing. In: Scientific Papers of University of Rzeszow: Zeszyty Naukowe Politechniki Rzeszowskiej : Mechanika z. 80. No. 273, p. 285-290. ISSN 0209-2689

Viňáš, J., Kaščák, L., Ábel, M., Draganovská, D., Gatial, M. (2010): Corrosion resistance of MIG soldered hot-dip galvanized sheets. In. Lebanese Science Journal, vol.11. no. 2 ISSN: 1561-3410

***(2007)http://www.sciencedirect.com/science/article/pii/S09 24013607003615

***(2004)http://www.sciencedirect.com/science/article/pii/S09 27796X04000105 